\title{
Trends in Well-Child Visits to Family Physicians by Children Younger Than 2 Years of Age
}

\section{Donna Coben, MD, MSc \\ Andrew Coco, MD, MS}

The Research Institute at Lancaster General Hospital, Department of Family and Community Medicine, Lancaster General Hospital, Lancaster, Pennsylvania

Conflicts of interest: none reported

\section{CORRESPONDING AUTHOR}

Donna Cohen, MD, MSc 555 North Duke St PO Box 3555

Lancaster, PA 17604

docohen@lancastergeneral.org

\begin{abstract}
PURPOSE Provision of prenatal visits by family physicians decreased by $50 \%$ from 1995 to 2004. To determine the impact of this trend on the provision of well-child visits by these professionals, we measured trends in and factors associated with well-child visits by children younger than 2 years of age to family physicians and pediatricians.
\end{abstract}

METHODS Using the National Ambulatory Medical Care Survey, we identified well-child visits made in the first 2 years of life to family physicians and pediatricians between 1995 and 2007. The primary outcome measure was the trend in the proportion of such visits that were specifically to family physicians.

RESULTS We identified a total of 4,999 visits, representing 213 million well-child visits at the national level. Compared with visits to pediatricians, visits to family physicians were associated with higher rates of Medicaid insurance $(P<.01)$ and were more likely to occur in non-metropolitan statistical area locations $(P<.01)$ and in the Midwest and West geographic regions $(P<.01)$. The percentage of all well-child visits for children younger than 2 years of age that were made to family physicians remained stable at 15\% (95\% confidence interval, 13\%-17\%; $P=.29$ for trend) during the study period.

CONCLUSIONS The diminishing role of family physicians in prenatal care has not been accompanied by a similar decrease in provision of well-child care to children younger than 2 years of age.

Ann Fam Med 2010;8:245-248. doi: 10.1370/afm.1076.

\section{INTRODUCTION}

recent study showed that between 1995 and 2004, there was a
significant reduction of nearly 50\% in the share of all outpatient
prenatal care visits in the United States that were provided by family physicians. ${ }^{1}$ One hypothesis, which has been cited in the literature and from anecdotal experience, is that a reduction in prenatal or obstetric care may result in a reduction in the care of children as the result of fewer infants entering family medicine practices and therefore lost to other health professionals who care for children. ${ }^{2-6}$ Recent studies indicate that family physicians have been experiencing a diminishing role in the proportion of outpatient care of children of all ages within the United States. ${ }^{2-4,7}$

To better understand whether the recent documented decline in prenatal visits to family physicians has affected the provision of preventive care for children younger than 2 years of age, we analyzed National Ambulatory Medical Care Survey (NAMCS) data for the years 19952007, using the same database used for the aforementioned study on prenatal care visits. ${ }^{1}$ 


\section{METHODS}

\section{National Ambulatory Medical Care Survey}

The NAMCS is administered by the National Center for Health Statistics (NCHS) for the Centers for Disease Control and Prevention (CDC) ${ }^{8}$ The NAMCS collects information on patient visits to office-based physician practices in the United States, including federally qualified health centers and nonfederal government clinics. The survey incorporates a multistage probability design, accounting for practice location, physician specialty, and individual visits within the practice.

Physicians are randomly selected from the master files of the American Medical Association and the American Osteopathic Association, and then randomly assigned to a 1 -week reporting period. During this period, data for a systematic random sample of visits are recorded by the physician or office staff on a standardized encounter form and checked for completeness by NCHS field staff.

The survey collected 348,881 patient visits between 1995 and 2007. ${ }^{8}$ The participation rate of contacted physician practices in the NAMCS ranged from $59 \%$ in 2005 to $73 \%$ in 1995 . Quality control was performed using a 2 -way independent verification procedure for $10 \%$ of the sample visits. In 2007, coding errors for various items ranged from $0 \%$ to $1.6 \%$.

The NCHS weights each visit to allow extrapolation to national estimates for all aspects of the survey. The weighting calculations account for practices that were invited to participate but declined to do so. National estimates are considered reliable with a standard error of $30 \%$ or less, which generally corresponds to a sample of at least 30 patient visits. ${ }^{8}$

\section{Study Variables}

Deidentified clinical and demographic data, including age, insurance status, and race, were collected for each visit. ${ }^{9}$ The NCHS institutional review board approved the protocol for the NAMCS, including a waiver of the requirement for informed consent. Health professional variables included self-reported specialty. Clinical variables included the primary diagnosis and up to 2 secondary diagnoses coded according to the International Classification of Diseases, Ninth Revision, Clinical Modification (ICD-9-CM). ${ }^{10}$ The NCHS divides the country into 4 geographic regions-Northeast, South, Midwest, and West_-in NAMCS. Rural locations were identified based on the designation of non-metropolitan statistical area by the US Office of Management and Budget.

We examined all office visits with the primary diagnoses of routine infant or child health check (ICD-9-CM codes V20, V20.1, V20.2), routine general medical examination (V70.0), and health examina- tion of defined subpopulations (V70.5). To most accurately capture the direct impact that the location, distribution, and timing of prenatal services by family physicians may have on well-child care, we limited well-child office visits to children younger than 2 years of age. We further categorized visits by children into 3 age categories: (1) younger than 6 months, (2) 6 to 12 months, and (3) 1 to 2 years. Additionally, we eliminated visits to physicians whose specialty was not family medicine/general practice or general pediatrics.

\section{Statistical Analysis}

We calculated standard errors (SEs) for all results as recommended by the NCHS using Stata software, version 10.0 (StataCorp, College Station, Texas). ${ }^{9}$ Stata was programmed with the masked survey design variables to take into account the complex multistage design of the survey that allows for making population estimates and generating variance estimates that result in conservative tests of significance. ${ }^{11}$ The NCHS weights each visit to permit extrapolation to national estimates for all aspects of the survey. We used these visit weights for all analyses.

We performed linear regression analysis with biennial period as the predictor variable to assess for a trend in the proportion of all US well-child visits by children younger than 2 years of age provided by family physicians. To decrease annual variation in visit estimates, we combined 2 successive years of data (1 year for the last period), as recommended by NCHS, for a total of 7 periods (1995-1996, 1997-1998, 19992000, 2001-2002, 2003-2004, 2005-2006, 2007) for the trend analysis.

Categorical variables were evaluated with the $\chi^{2}$ test. All statistical tests take into account data from all 13 years, from 1995 through 2007. All $P$ values are 2tailed, $P<.05$ was considered significant.

\section{RESULTS}

After we applied inclusion and exclusion criteria to the NAMCS data, a total of 4,999 visits $(4,264$ to general pediatricians and 735 to family physicians) remained for analysis At the national level, this survey sample represented an estimated 213 million well-child visits in the United States between 1995 and 2007, with 181 million visits to general pediatricians and 32 million visits to family physicians.

Characteristics of the well-child visits grouped by physician specialty are shown in Table 1. Compared with visits to pediatricians, visits to family physicians were associated with higher rates of Medicaid insurance $(P<.01)$ and were more likely to occur in nonmetropolitan statistical area locations $(P<.01)$ and in 


\begin{tabular}{|c|c|c|c|}
\hline \multirow[b]{2}{*}{ Characteristic } & \multicolumn{2}{|c|}{ Proportion of Visits, \% } & \multirow[b]{2}{*}{$P$ Value } \\
\hline & $\begin{array}{l}\text { Family Physicians } \\
(\mathrm{n}=735)\end{array}$ & $\begin{array}{l}\text { Pediatricians } \\
(n=4,264)\end{array}$ & \\
\hline \multicolumn{4}{|l|}{ Age } \\
\hline$<6$ months & 51.8 & 47.2 & .06 \\
\hline 6-12 months & 22.4 & 21.5 & \\
\hline $1-2$ years & 25.8 & 31.3 & \\
\hline \multicolumn{4}{|l|}{ Race } \\
\hline White & 79.0 & 74.5 & .20 \\
\hline Black & 7.6 & 9.5 & \\
\hline Other & 13.4 & 16.0 & \\
\hline \multicolumn{4}{|l|}{ Ethnicity } \\
\hline Latino & 18.4 & 18.5 & .82 \\
\hline \multicolumn{4}{|l|}{ Health insurance } \\
\hline Private & 44.7 & 61.9 & $<.01$ \\
\hline Medicaid & 35.4 & 23.4 & \\
\hline Other & 19.9 & 14.7 & \\
\hline \multicolumn{4}{|l|}{ Geographic region } \\
\hline Northeast & 11.6 & 26.1 & $<.01$ \\
\hline Midwest & 38.9 & 20.6 & \\
\hline South & 20.3 & 27.6 & \\
\hline West & 29.2 & 25.8 & \\
\hline \multicolumn{4}{|l|}{ Geographic entity } \\
\hline $\begin{array}{l}\text { non-metropolitan } \\
\text { statistical area }\end{array}$ & 34.9 & 8.9 & $<.01$ \\
\hline
\end{tabular}

the Midwest and West geographic regions $(P<.01)$. There was no significant difference between specialties in the rate of visits by age category $(P=.06)$.

The primary outcome of analysis was the trend in the proportion of all wellchild visits in the first 2 years of life to family physicians in US physician offices, as shown in Figure 1. During the 13-year study period, the percentage of well-child visits by children in this age-group to family physicians remained steady at 15\% (95\% confidence interval, 13\%-17\%), varying from $16 \%$ in $1995-1996$ to $14 \%$ in 2007 $(P=.29$ for trend).

\section{DISCUSSION}

This study used a nationally representative survey to characterize the contribution of family physicians to well-child care in the first 2 years of life. Despite a significant decline in the provision of prenatal services by family physicians between 1995 and 2004 from $11.6 \%$ to $6.1 \%,{ }_{1}$, family physicians provided a stable share of well-child care in the first 2 years of life

Figure 1. Trend in the proportion of well-child visits by children younger than 2 years of age to family physicians.

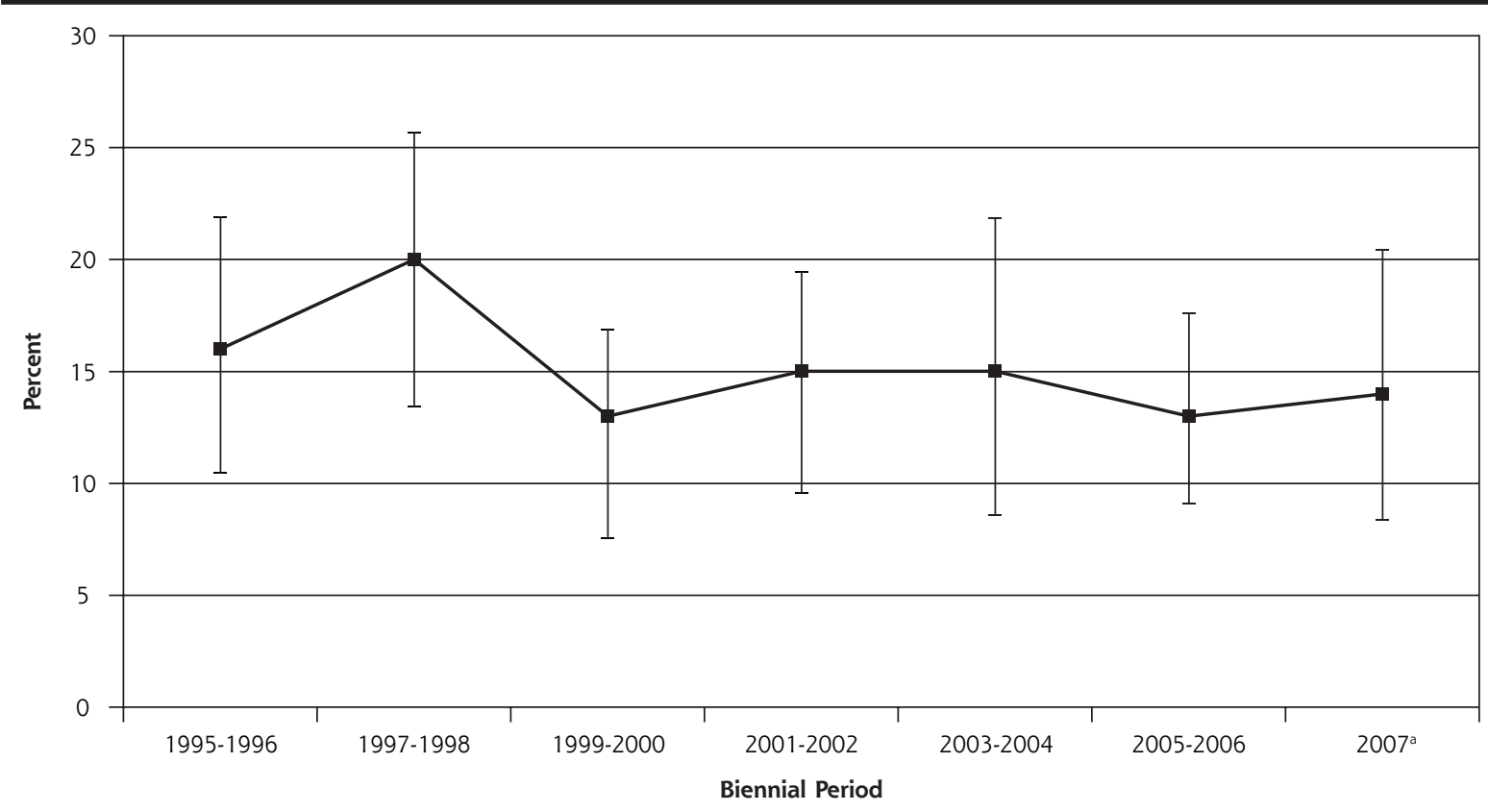

Notes: National estimates based on 4,999 well-child visits by children younger than 2 years of age in the National Ambulatory Medical Care Survey, 1995-2007. For trend, $P=.29$. Vertical bars represent $95 \%$ confidence intervals.

a Last period (2007) encompassed 1 year instead of 2 years because of odd number of years in the study time period. 
over a similar time period. These findings suggest that a decline in prenatal services is not a likely contributing factor to the recent decline in outpatient care for children of all ages by family physicians within the United States. In addition, the findings challenge the argument historically used within family medicine that stopping maternity care may leave physicians with an older practice population, resulting in fewer children and young families for whom to care.

Because of limitations of the data, we were unable to establish direct, causal associations between provision of prenatal care and early well-child care, or evaluate differences in patient outcomes between specialties.

In conclusion, despite recent evidence that family physicians have significantly reduced their contribution to prenatal care in recent years, this study demonstrates that they have continued to make a substantial contribution to well-child care in the first 2 years of life. This finding challenges the long-standing belief that a reduction in maternity care is associated with a reduction in care for children.

To read or post commentaries in response to this article, see it online at http://www.annfammed.org/cgi/content/full/8/3/245.

Key words: Trends in well-child care; children; well-infant care; family medicine; primary care; preventive health services; health services research

Submitted May 13, 2009; submitted, revised, September 29, 2009; accepted October 6, 2009.

A version of this report was presented at the 2008 American Academy of Family Physicians Scientific Assembly in San Diego, California; the 2008 North American Primary Care Research Group Annual Conference in Puerto Rico; and the 2009 Society of Teachers of Family Medicine Annual Conference in Denver, Colorado.

\section{References}

1. Cohen D, Coco A. Declining trends in the provision of prenatal care visits by family physicians. Ann Fam Med. 2009;7(2):128-133.

2. Freed GL, Nahra TA, Wheeler JRC. Which physicians are providing health care to America's children? Trends and changes during the past 20 years. Arch Pediatr Adolesc Med. 2004;158(1):22-26.

3. Phillips RL, Dodoo MS, McCann JL, et al. Report to the Task Force on the Care of Children by Family Physicians. Washington, DC: The Robert Graham Center for Policy Studies in Family Medicine and Primary Care in collaboration with the American Academy of Pediatrics Center for Child Health Research; 2005.

4. Backer LA. Caring for children: re-examining the family physician's role. Fam Pract Manag. 2005;12(7):45-52.

5. Turkal N, Christman C. Graduates comment on issues related to the decline of Wisconsin family physicians providing maternity care. Wis Med J. 1996;95(1):17-21.

6. Barr WB. Why pregnancy care should be an essential part of family medicine training. Fam Med. 2005;37(5):364-366.

7. Robert Graham Center. Policy studies in family medicine and primary care. The diminishing role of FPs in caring for children. Am Fam Physician. 2006;73(9):1518.

8. Hing E, Cherry DK, Woodwell DA. National Ambulatory Medical Care Survey: 2004 Summary: Advance Data From Vital and Health Statistics. No. 374. Hyattsville, MD: National Center for Health Statistics; 2006

9. National Center for Health Statistics. Public Use Microdata File Documentation, National Ambulatory Medical Care Survey, 2004. Hyattsville, MD: National Technical Information Service; 2006.

10. Centers for Disease Control and Prevention. International Classification of Diseases, Ninth Revision, Clinical Modification (ICD-9-CM). http://www.cdc.gov/nchs/icd/icd9cm.htm. Accessed Apr 15, 2007.

11. Hing E, Gousen S, Shimizu I, Burt C. Guide to using masked design variables to estimate standard errors in public use files of the National Ambulatory Medical Care Survey and the National Hospital Ambulatory Medical Care Survey. Inquiry. 2003:40(4):401-415. 